\title{
Proposta de classificação de barragens quanto ao dano potencial associado para o estado de Roraima
}

Tendo em vista que a análise do potencial de perdas de vidas humanas, bem como impactos ambientais e socioeconômicos que ocorrem na área de inundação, em caso de possíveis rupturas de barragens, contribuem para elaboração do Plano de Segurança de Barragens - PSB e que tais análises fazem parte dos objetivos e instrumentos da Política Nacional de Segurança de Barragens - PNSB, analisa-se os critérios aplicados à classificação de barragens quanto ao Dano Potencial Associado - DPA que reflitam melhor a realidade dos barramentos estudados, a fim de propor um modelo de classificação para o estado de Roraima, baseado no estudo de caso de sete barragens situadas na bacia do Rio Cauamé. Para tanto, é necessário analisar a classificação apresentada pelas Resoluções Conselho Nacional de Recursos Hídricos - CNRH n. 143/2012 e Agência Nacional de Águas - ANA n. 132/2016 quando aplicadas aos barramentos do estado de Roraima, analisar de maneira comparativa a classificação das barragens quanto ao DPA utilizando o método simplificado de geração de mancha de inundação e a classificação feita pela Roraima, analisar de maneira comparativa a classificação das barragens quanto ao DPA utilizando o método simplificado de geração de mancha de inundação e a classificação feita pela
Fundação Estadual do Meio Ambiente e Recursos Hídricos - Femarh, órgão fiscalizador estadual, com critérios próprios e apresentar proposta de classificação de barragens quanto ao DPA utilizando metodologias complementares, associada à Instrução Normativa - IN Femarh n. 3/2017 e à Resolução ANA n. 132/2016. Realiza-se, então, pesquisa do tipo bibliográfica e documental acerca de qual metodologia deve ser utilizada para delimitação da área afetada, bem como quais critérios e pontuações melhor se adequam à realidade dos barramentos estudados, de modo a embasar a proposta apresentada a partir de uma abordagem qualitativa de dados. Diante disso, verifica-se que os critérios estabelecidos nas Resoluções CNRH $\mathrm{n}$. 143/2012 e ANA n. 132/2016 penalizaram em excesso as barragens, sem distribuição quantitativa adequada à realidade das barragens do estado quanto ao impacto socioeconômico. Ademais, quanto aos critérios presentes na IN Femarh n. 3/2017, observa-se que houve divergências relevantes na classificação obtida, já que a Femarh não possui critérios bem definidos para delimitação da área afetada o que pode ter a subestimada, resultando em uma classificação incompatível com a realidade. Assim, verifica-se que a proposta apresentada pondera os critérios já estabelecidos a nível nacional e internacional, alterando faixas de classificações e inserindo critérios quantitativos, de modo a reduzir a discricionariedade por parte do órgão fiscalizador, o que permite a constatação de que o modelo de classificação proposto reflete as boas práticas utilizadas, sendo adequado ao estado de Roraima.

\section{Proposed classification of dams in terms of potential damage associated with the state of Roraima}

\begin{abstract}
Considering that the analysis of the potential loss of human life, as well as environmental and socioeconomic impacts that occur in the flood area, in the event of possible dam breaks, contribute to the elaboration of the Dam Safety Plan - DSP and that such analyzes are part of the objectives and instruments of the National Dam Safety Policy - NDSP, analyze the criteria applied to the hazard potential rating of dams that reflect in the best way the reality of the studied dams, in order to propose a rating model for the state of Roraima, based on the case study of seven dams located in the basin of the Cauamé River. Therefore, it's necessary to analyze a rating published by resolutions National Water Resources Council - NWRC n. 143/2012 and National Water Agency - NWA n. 132/2016, when applied to the dams of the state of Roraima, to analyze in the comparative way the hazard potencial rating, using the simplified flood spot generation method and the rating made by Fundação Estadual do Meio Ambiente e Recursos Hídricos - Femarh, state supervisory sector, with its own criteria and present a proposal for the hazard potential rating of dams using complementary methodologies, associated with Normative Instruction - IN Femarh n. 3/2017 and ANA Resolution n. 132/2016. A bibliographic and documentary research is carried out about which methodology should be used to delimit the affected area, as well as which criteria and scores are best suited to the reality of the studied dams, in order to support the proposal presented from of a qualitative approach to data. That said, the criteria established in resolutions CNRH n. 143/2012 and ANA $\mathrm{n}$. 132/2016 penalized in excess the dams, without a quantitative distribution adequate to the reality of the state dams as to the socioeconomic impact. In addition, about the Normative Instruction Femarh $n$. in excess the dams, without a quantitative distribution adequate to the reality of the state dams as to the socioeconomic impact. In addition, about the Normative Instruction Femarh $\mathrm{n}$.
$3 / 2017$, check that there were some relevant divergences in the rating, because Femarh doesn't have well-defined criteria to delimit the affected area or may have underestimated the specific area, resulting in an incompatible rating with reality. Thus, the proposal presented weighs the criteria already established at national and international level, changing ranges of ratings and inserting quantitative criteria, in order to reduce the discretion of the supervisory sector, which allows the verification that the model of proposed rating reflects the good practices used, being appropriate to the state of Roraima.
\end{abstract}

Keywords: Dam; Hazard potential rating; Classification.

Topic: Planejamento, Gestão e Políticas Públicas Ambientais

Reviewed anonymously in the process of blind peer.

Andressa dos Santos Pereira (iD)

Universidade Federal de Roraima, Brasil

http://orcid.org/0000-0002-2854-9762

engcivilandressa@hotmail.com

Adriano Frutuoso da Silva (iD

Universidade Federal de Roraima, Brasil

http://lattes.cnpq.br/3321059172343690

http://orcid.org/0000-0003-1710-8862

adriano.silva@ufrr.br

Silvestre Lopes da Nóbrega (iD

Universidade Federal de Roraima, Brasil

http://lattes.cnpq.br/4455976974263748

http://orcid.org/0000-0002-5931-7550

silvestre.lopes@ufrr.br

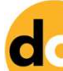

DOI: 10.6008/CBPC2179-6858.2021.003.0054
Received: 03/03/2021

Approved: 25/03/2021

Maola Monique Faria (iD)

Universidade Federal de Roraima, Brasil

http://lattes.cnpq.br/9786532121315580

http://orcid.org/0000-0001-7556-4968

maolageo@gmail.com
Referencing this:

PEREIRA, A. S.; SILVA, A. F.; NÓBRIGA, S. L.; FARIA, M. M.. Proposta de classificação de barragens quanto ao dano potencial associado para o estado de Roraima. Revista Ibero Americana de Ciências Ambientais, v.12, n.3, p.679-695, 2021. DOI: http://doi.org/10.6008/CBPC2179$\underline{6858.2021 .003 .0054}$ 


\section{INTRODUÇÃO}

Tratar sobre questões de segurança das barragens é essencial para redução de possibilidades de desastres e crimes ambientais, considerando o risco potencial de ruptura ou outro acidente grave, bem como sua área de impacto no âmbito humano, social, ambiental e econômico-financeiro.

Tendo em vista que risco é a combinação da probabilidade de um evento com a sua consequência, Anderáos et al. (2013) consideram que, de certo modo, o mais importante dos sete instrumentos da Política Nacional de Segurança de Barragens - PNSB, estabelecida pela Lei Federal n· 12.334/2010, é o sistema de classificação de barragens, por categoria de risco, por dano potencial associado e por volume. Os autores constataram ainda que tal sistema deverá ser o dosador das medidas e procedimentos de monitoramento a serem adotados, de forma a tornar mais seguras as barragens, determinando a periodicidade e o conteúdo mínimo das inspeções regulares e especiais, da revisão periódica, e a obrigatoriedade ou não de elaboração do Plano de Ação Emergencial - PAE da barragem, segundo regulamentos a serem publicados pelos agentes fiscalizadores da segurança de barragens.

Os critérios para classificação da barragem quanto ao Dano Potencial Associado - DPA levam em consideração a área afetada, ou seja, a área à jusante e montante potencialmente comprometidos por eventual ruptura da barragem, cuja metodologia de definição de seus limites deverá ser determinada pelo órgão fiscalizador.

No estado de Roraima, de modo a regulamentar a Resolução Conselho Nacional de Recursos Hídricos - CNRH n. 143/2012, foi publicada pelo órgão fiscalizador estadual, Fundação Estadual do Meio Ambiente e Recursos Hídricos - Femarh, a Instrução Normativa - IN Femarh n. 3/2017 (FEMARH, 2017). Contudo, de acordo com Agência Nacional de Águas - ANA (2017), todos os barramentos existentes, comunicados até a data da pesquisa, foram construídos anteriormente à Legislação Federal n. 12.334/2010 e até mesmo à instituição formal do órgão responsável pelo seu cadastro, regularização e fiscalização. Deste modo, as barragens não foram inseridas no sistema nacional de barragens devido a grande maioria não estarem regularizadas, estando em fase de elaboração instrumento legal para regularização daquelas.

A identificação e o cadastro das barragens são essenciais para classificação quanto ao DPA, a qual é realizada em função do potencial de perdas de vidas humanas e dos impactos econômicos, sociais e ambientais decorrentes da ruptura da barragem. Se não há conhecimento sobre a existência de determinada barragem, não há classificação, o que implica dizer que nada se sabe acerca do dano potencial naquela área afetada.

Deste modo, pesquisa-se sobre critérios aplicados à classificação de barragens quanto ao DPA que reflitam melhor a realidade dos barramentos estudados, a fim de propor um modelo de classificação para o estado de Roraima, baseado no estudo de caso de sete barragens situadas na bacia do Rio Cauamé. Para tanto, foi necessário analisar a classificação apresentada pelas Resoluções CNRH n. 143/2012 e ANA n. 132/2016 quando aplicadas aos barramentos do estado de Roraima, analisar de maneira comparativa a classificação das barragens quanto ao DPA utilizando o método simplificado de geração de mancha de 
inundação e a classificação feita pela Femarh, órgão fiscalizador estadual, com critérios próprios e apresentar proposta de classificação de barragens quanto ao DPA utilizando metodologias complementares, associada à IN Femarh n. 3/2017 e à Resolução ANA n. 132/2016.

A classificação quanto ao DPA das barragens situadas na bacia do Cauamé poderá contribuir para elaboração do PSB, proporcionando dados concretos que possam ser utilizados posteriormente pelo órgão fiscalizador e otimizando inclusive os serviços de fiscalização quanto as inspeções, definição de obras prioritárias, critérios objetivos de avaliação, planos de ação de risco, entre outros, que serão definidos em função do DPA das barragens. Destaca-se que a periodicidade mínima da Revisão Periódica de Segurança de Barragem, de acordo com ANA (2017), será definida em função da matriz de Categoria de Risco - CRI e DPA da barragem, evidenciando-se assim a sua grande importância.

Para tanto, esta pesquisa partiu da hipótese de que a melhor maneira de propor um modelo de classificação de barragens quanto ao DPA, aplicável à realidade local, é alterar as pontuações de cada faixa de classificação, uma vez que as barragens do estado de Roraima são de pequeno porte, não havendo a necessidade de pontuações que culminem no excesso de penalização.

\section{MATERIAIS E MÉTODOS}

Inicialmente foi realizada pesquisa bibliográfica sobre classificação das barragens quanto ao DPA, que se buscou evidenciar as faixas de classificação utilizadas quanto ao volume, potencial de perdas de vidas humanas, impacto ambiental e socioeconômico, bem como a metodologia de delimitação da área afetada à jusante em caso de possível ruptura da barragem.

A nível internacional, a coleta de dados restringiu-se a países federativos utilizados como referência fundamental para a elaboração da Lei de Segurança de Barragens no Brasil por possuírem lei de segurança de barragens, arcabouço técnico já estabelecido em relação à segurança de barragens, classificação das barragens baseada em consequências, entre outros, tais como África do Sul, Austrália, Canadá e Portugal.
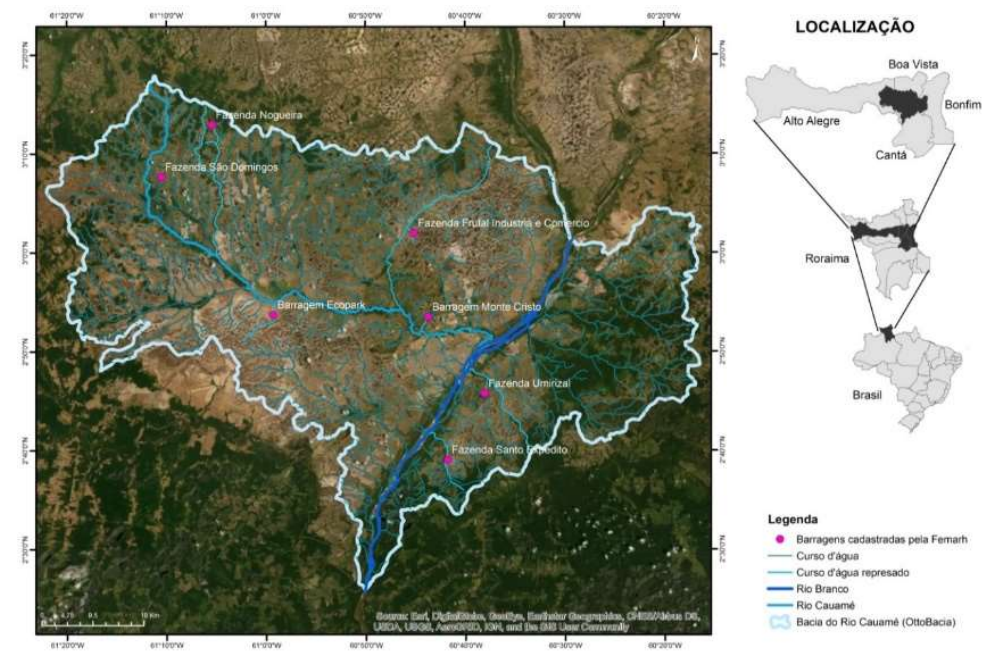

Figura 1: Localização da Bacia hidrográfica do Rio Cauamé, Roraima.

Já a nível nacional, optou-se por estados que já possuíssem bastante experiência com barragem, tais como Ceará e São Paulo. Além disso, foi considerada a complexidade de gestão nos estados, apresentada 
pelo Programa de Consolidação do Pacto Nacional pela Gestão das Águas - Progestão, distribuídas em quatro tipologias (ANA, 2020), sendo estudados os estados de Roraima, Rondônia e Paraná.

O desenvolvimento do estudo foi baseado na bacia hidrológica do Rio Cauamé. Assim, foram analisadas as barragens cadastradas na referida bacia pelo órgão fiscalizador estadual, Femarh, localizada nos municípios de Alto Alegre, Boa Vista, Bonfim e Cantá no estado de Roraima, conforme Figura 1 abaixo, baseada na codificação de Otto Pfafstetter, de nível 4, utilizada pelo órgão.

Todas as barragens estudadas foram barragens de terra, possuindo características físicas e classificação quanto ao DPA, conforme Quadro 1 abaixo (ANA, 2017b).

Quadro 1: Dados das barragens cadastradas pela Femarh na bacia do Rio Cauamé

\begin{tabular}{|c|c|c|c|c|c|c|c|}
\hline Barragem & Altura (m) & Volume do reservatório $\left(\mathrm{hm}^{3}\right)$ & Comprimento $(\mathrm{m})$ & Uso principal & Lat. & Long. & DPA \\
\hline EcoPark & 5,0 & 8,6 & 383,0 & Outros & 2,8955 & $-60,988$ & Alto \\
\hline Fazenda Frutal & 3,7 & 0,8 & 500,0 & Aquicult. & 3,03275 & $-60,752$ & Baixo \\
\hline Fazenda Nogueira & 11,5 & 7,3 & 275,0 & Outros & 3,21553 & $-61,089$ & Baixo \\
\hline Fazenda São Domingos & 7,5 & 3,3 & 469,5 & Aquicult. & 3,12765 & $-61,176$ & Baixo \\
\hline Fazenda Santo Expedito & 4,7 & 1,2 & 405,6 & Aquicult. & 2,651496 & $-60,6959$ & Baixo \\
\hline Fazenda Umirizal & 1,9 & 0,08 & 176,4 & - & 2,762996 & $-60,6341$ & Baixo \\
\hline Monte Cristo & 6,9 & 2,5 & 285,0 & Outros & 2,89136 & $-60,728$ & Baixo \\
\hline
\end{tabular}

Fonte: Adaptado de ANA (2017b).

\section{Delimitação da área afetada}

O método simplificado de geração de mancha de inundação foi utilizado neste estudo, uma vez que este abrange de maneira conservadora as experiências internacionais e nacionais. Desenvolvido pela ANA e o Laboratório Nacional de Engenharia Civil - LNEC de Portugal, o método correlaciona a distância inundada a jusante de uma barragem com os parâmetros conhecidos como volume e altura da barragem, usando uma base de dados de 145 casos de rompimentos de barragens compilados pelo United States Army Corps of Engineers - USACE (PETRY et al., 2018).

A princípio, de acordo com ANA (2017a), o método utiliza imagens de Modelo Digital de Elevação MDE do radar Shuttle Radar Topography Mission - SRTM, cuja resolução espacial é de 30,0 m. Contudo, considerando que a bacia em estudo está inserida em uma região de planície, optou-se por utilizar imagens do satélite Advanced Land Observing Satellite - ALOS sensor Phased Array L-band Synthetic Aperture Radar - PALSAR, cuja resolução espacial é de 12,5 m, obtidas junto ao Alaska Satellite Facility - ASF.

Para aplicação da metodologia simplificada foram necessários como dados de entrada, valores de altura $(\mathrm{m})$ e capacidade $\left(\mathrm{hm}^{3}\right)$ das barragens em estudo, obtidos por meio do Sistema Nacional de Informações sobre Segurança de Barragens - SNISB conforme apresenta ANA (2017b).

Nesta etapa, foi realizado o traçado manual do curso d'água represado a partir do barramento e percorrendo a distância máxima calculada à jusante, conforme Eq. 1, baseado no MDE, na rede hidrológica e nas imagens do ArcMap disponíveis da área analisada. Em seguida, foi gerada uma versão suavizada do traçado eliminando curvas acentuadas.

$$
D_{\text {máx }}=8,870 \times 10^{-8} V_{\text {máx }}{ }^{3}-2,602 \times 10^{-4} V_{\text {máx }}{ }^{2}+2,648 \times 10^{-1} V_{\text {máx }}+6,737 \quad \text { Eq. } 1
$$

Sendo $V_{\text {máx }}$ o volume máximo do reservatório e a equação válida para volumes de reservatório até $1.000,0 \mathrm{hm}^{3}$. Para geração de manchas de inundação foi necessário traçar 21 seções de 4,0 km de largura, de acordo com ANA (2017a), distribuídas igualmente e aproximadamente perpendiculares ao longo do 
comprimento do traçado do curso d'água suavizado, à jusante da barragem. Cada uma das seções foi representada por 81 pontos totalizando 1701, que são confrontados com o MDE, obtendo-se automaticamente, por interpolação, as respectivas cotas altimétricas e, por conseguinte, foi gerada uma superfície de máxima de inundação.

De maneira conservadora foi realizado um buffer moderado em torno no curso d'água represado de 150,0 m, de acordo com ANA (2017a), de modo a considerar possíveis desvios entre a localização do talvegue digitalizado e a localização do talvegue obtida por imagens do MDE, utilizada no estudo. Além disso, o procedimento permitiu que, nos casos em que as áreas de inundação eram descontínuas ao longo da linha de água, foram tornadas contínuas.

Para melhor assimilação da metodologia aplicada, foi utilizada como exemplo do processo executado em todos os barramentos, a barragem da Fazenda Umirizal ao decorrer da descrição dos materiais e métodos adotados para delimitação da área afetada. Assim, a mancha de inundação final foi obtida, após todas as correções manuais descritas acima, conforme Figura 2.

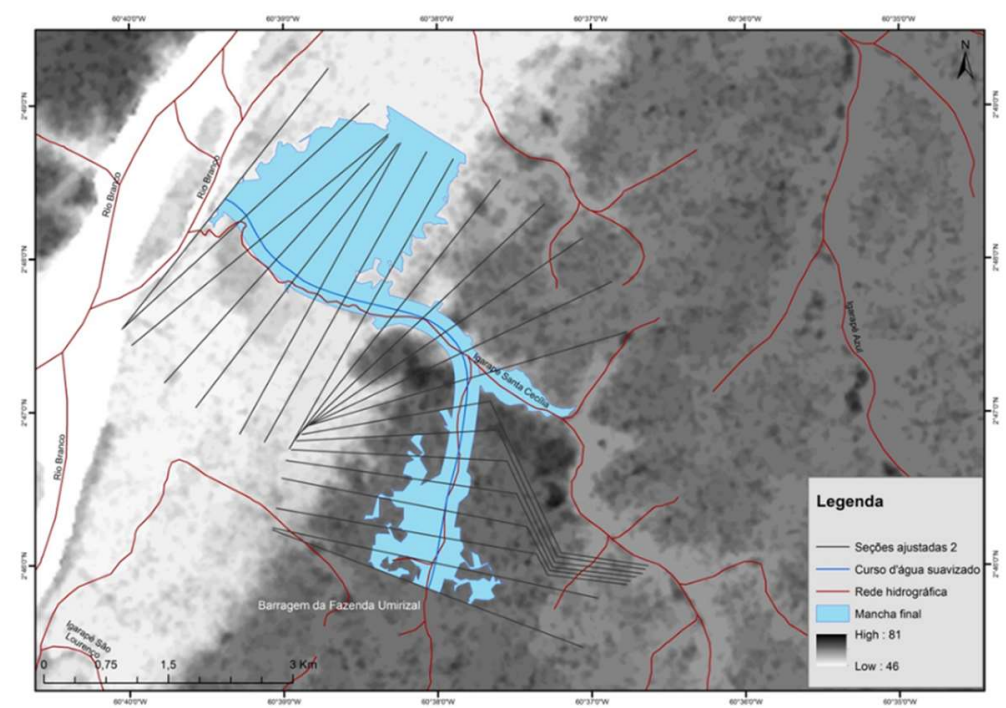

Figura 2: Mancha de inundação final após correções da barragem da Fazenda Umirizal.

\section{Classificação quanto ao DPA das barragens}

Para a classificação das barragens quanto ao DPA, foi utilizado o método simplificado de geração de mancha de inundação, por se considerar mais consistente, uma vez que foi elaborado baseado em estudos de rupturas e experiências de outros países.

Assim, para obtenção da classificação, foram aplicados os critérios apresentados pelas Resoluções CNRH n. 143/2012 e ANA n. 132/2016 de modo a serem analisados seus resultados quanto ao grau de penalização dos barramentos quando considerada a realidade local.

Além disso, a partir dos critérios presentes na IN Femarh n. 3/2017, associados à aplicação do método simplificado de geração de mancha de inundação, foi feita uma análise comparativa entre a classificação obtida e a apresentada pela Femarh, de acordo com ANA (2017b).

Para tanto, de acordo com cada critério analisado foi utilizado como base de dados para classificação o que consta no Quadro 2. 
Quadro 2: Base de dados utilizada para classificação das barragens.

\begin{tabular}{|l|l|}
\hline Critério & Base de dados \\
\hline Volume & SNISB (ANA, 2017b) \\
\hline Potencial de perdas de vidas humanas & Google Earth e IBGE (IBGE, 2011) \\
\hline Impacto ambiental & IBGE (IBGE, 2011) \\
\hline Impacto socioeconômico & Google Earth e IBGE (IBGE, 2011) \\
\hline
\end{tabular}

\section{Elaboração da proposta de classificação quanto ao DPA}

Seguindo o critério mais conservador, foi elaborada uma proposta de classificação quanto ao DPA, aplicada às barragens do estado de Roraima, de modo que os critérios de classificação propostos foram baseados na situação local, considerando o porte das barragens, bem como a área de inundação obtida pelo método simplificado de geração de mancha, de acordo com ANA (2017a).

Ressalta-se que não foi feita nenhuma alteração nas pontuações atribuídas pela Resolução CNRH n. 143/2012, Resolução ANA n. 132/2016 ou IN Femarh n. 3/2017, quando utilizadas como parâmetros para proposta, uma vez que, de acordo com Banco Mundial (2014), as pontuações consideradas permitem espelhar de forma correta o peso relativo dos danos, com ênfase em particular ao potencial de perdas de vidas humanas.

\section{RESULTADOS E DISCUSSÃO}

A seguir são apresentados os resultados obtidos a partir do presente estudo, apresentando as classificações analisadas que contribuíram para elaboração do modelo de proposta de classificação de barragens quanto ao DPA.

\section{Proposta de classificação das barragens quanto ao DPA para o estado de Roraima}

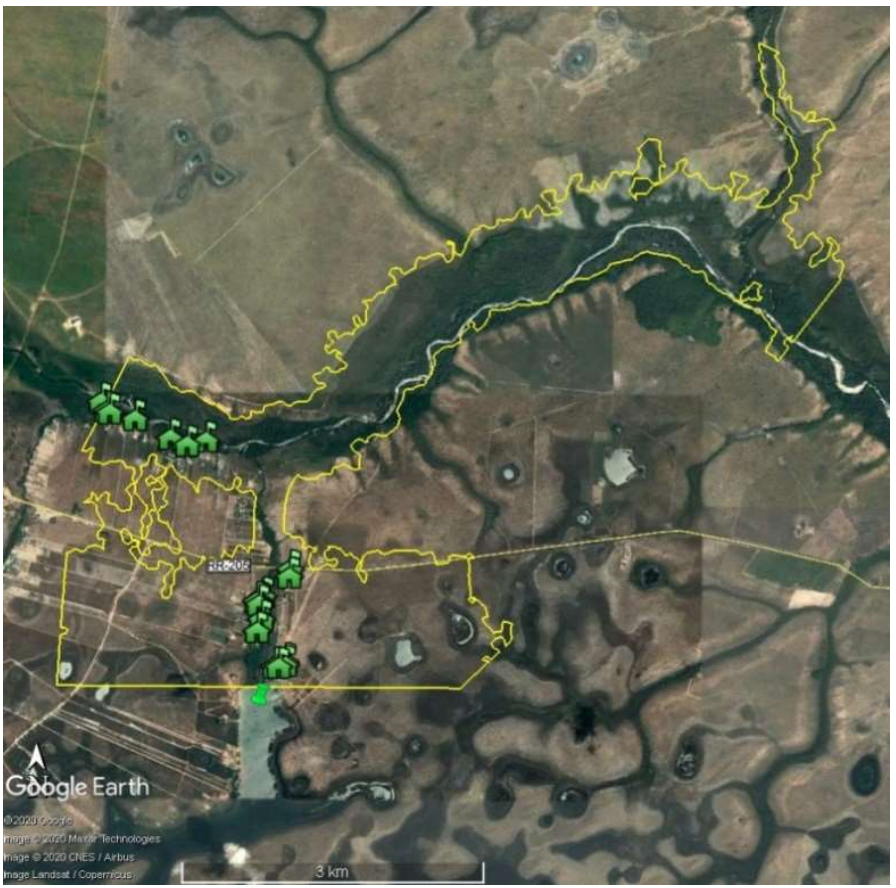

\begin{tabular}{|c|c|c|}
\hline \multicolumn{2}{|c|}{ Legenda } & Observações \\
\hline Área & & $\begin{array}{c}\text { Mancha de 13,2 } \\
\text { km² atinge RR } \\
\text { 205, o Igarapé } \\
\text { inundada } \\
\text { Caumauá e o Rio } \\
\text { tanques dém de } \\
\text { piscicultura. }\end{array}$ \\
\hline $\begin{array}{c}\text { Residências } \\
\text { isoladas }\end{array}$ & $\&$ & $\begin{array}{c}\text { Há } \\
\text { aproximadamente } \\
23 \text { residências. }\end{array}$ \\
\hline $\begin{array}{c}\text { Barragem } \\
\text { analisada }\end{array}$ & $\&$ & - \\
\hline
\end{tabular}

Figura 3: Mancha de inundação da barragem Ecopark.

Baseada nas penalizações excessivas observadas quando aplicados os critérios estabelecidos na 
Resolução CNRH n. 143/2012 e ANA n. 132/2016, bem como na IN Femarh n. 3/2017, se fez necessário analisar os parâmetros utilizados para classificação das barragens quanto ao DPA, utilizando como metodologia para delimitação da área afetada a geração de mancha de inundação (ver Figuras 3 a 9), uma vez que a Femarh não possui nenhuma.

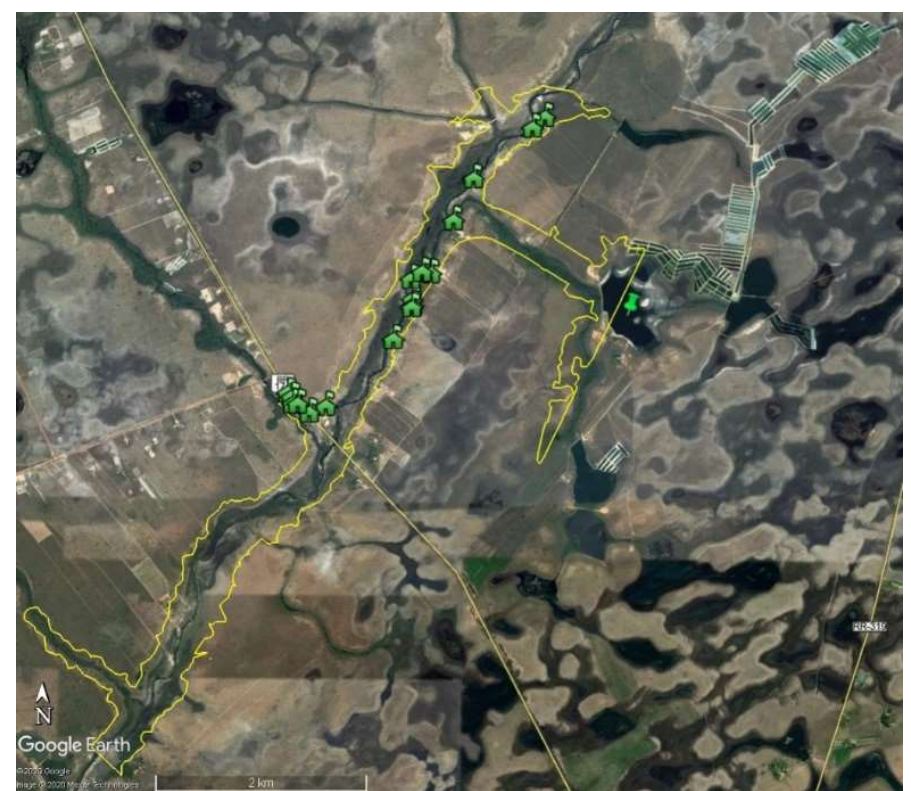

\begin{tabular}{|c|c|c|}
\hline \multicolumn{2}{|c|}{ Legenda } & Observações \\
\hline $\begin{array}{c}\text { Área } \\
\text { inundada }\end{array}$ & $\begin{array}{c}\text { Mancha de 4,4 } \\
\text { km² atinge BR 174 } \\
\text { e os Igarapés: } \\
\text { Murupu, Sucurijá, } \\
\text { Água Branca e 1 } \\
\text { sem nome, além } \\
\text { de tanques de } \\
\text { piscicultura. }\end{array}$ \\
\hline $\begin{array}{c}\text { Residências } \\
\text { isoladas }\end{array}$ & Há \\
\hline $\begin{array}{c}\text { Barragem } \\
\text { analisada }\end{array}$ & $\&$ & $\begin{array}{c}\text { aproximadamente } \\
23 \text { residências. }\end{array}$ \\
\hline
\end{tabular}

Figura 4: Mancha de inundação da barragem da Fazenda Frutal.

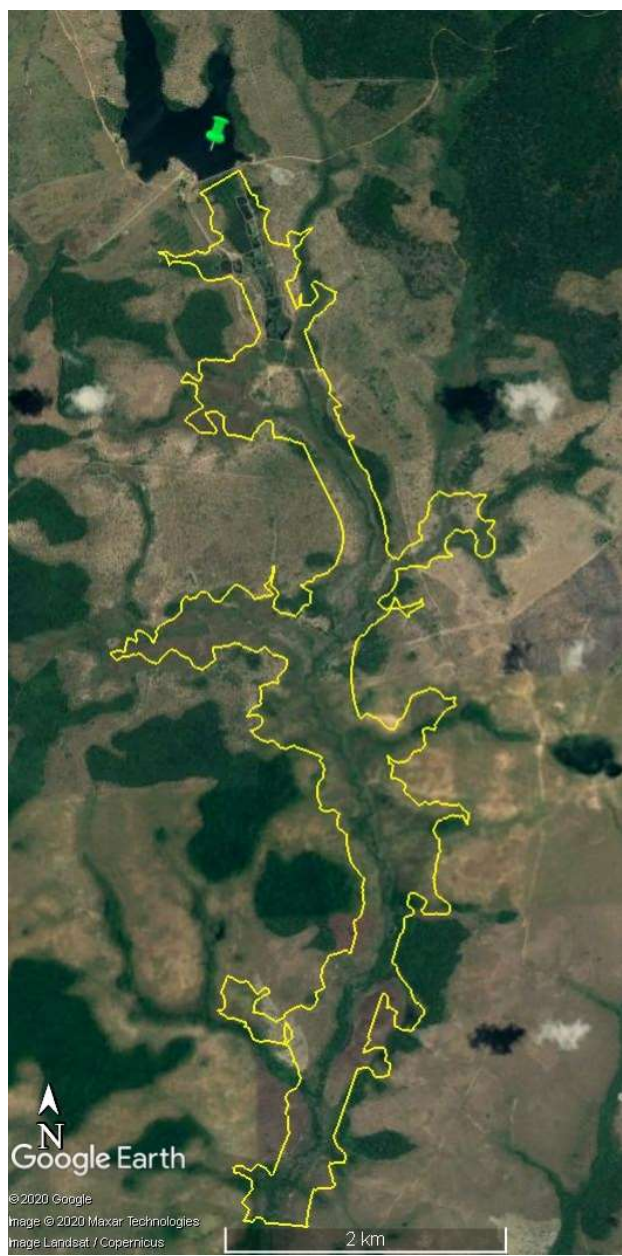

\begin{tabular}{|c|c|c|}
\hline \multicolumn{2}{|c|}{ Legenda } & Observações \\
\hline $\begin{array}{c}\text { Área } \\
\text { inundada }\end{array}$ & $\begin{array}{c}\text { Mancha de 4,8 } \mathrm{km}^{2} \text { atinge } \\
\text { os Igarapés: Lontra, do } \\
\text { Jairo e 1 sem nome, além } \\
\text { de tanques de piscicultura. }\end{array}$ \\
\hline $\begin{array}{c}\text { Barragem } \\
\text { analisada }\end{array}$ & $\wp$ & - \\
\hline
\end{tabular}

Figura 5: Mancha de inundação da barragem Fazenda Nogueira. 
PEREIRA, A. S.; SILVA, A. F.; NOBBRIGA, S. L.; FARIA, M. M.

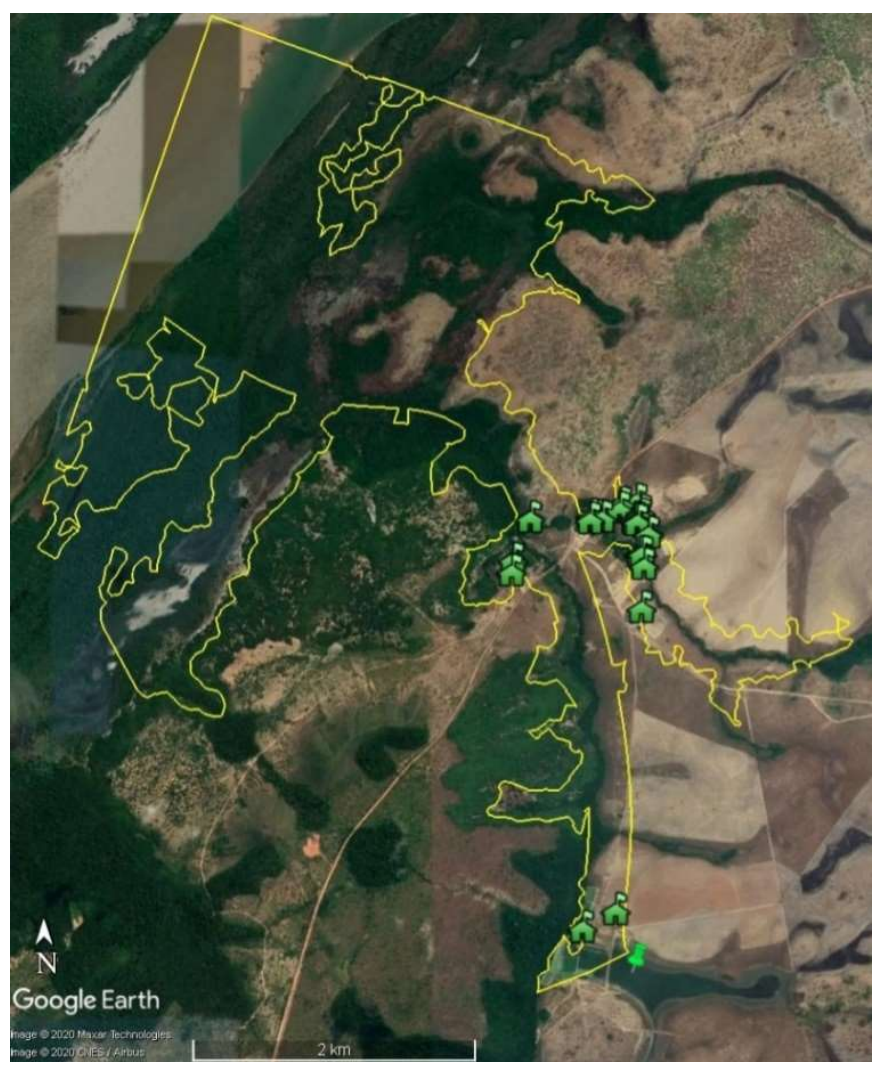

\begin{tabular}{|c|c|}
\hline Legenda & Observações \\
\hline $\begin{array}{c}\text { Área } \\
\text { inundada }\end{array}$ & $\begin{array}{l}\text { Mancha de } 11,1 \mathrm{~km}^{2} \\
\text { atinge dois Igarapés sem } \\
\text { nomes e vicinais, além de } \\
\text { tanques de piscicultura. }\end{array}$ \\
\hline $\begin{array}{c}\text { Residências } \\
\text { isoladas }\end{array}$ & $\begin{array}{l}\text { Há aproximadamente } 23 \\
\text { residências. }\end{array}$ \\
\hline $\begin{array}{l}\text { Barragem } \\
\text { analisada }\end{array}$ & - \\
\hline
\end{tabular}

Figura 6: Mancha de inundação da barragem Fazenda Santo Expedito.

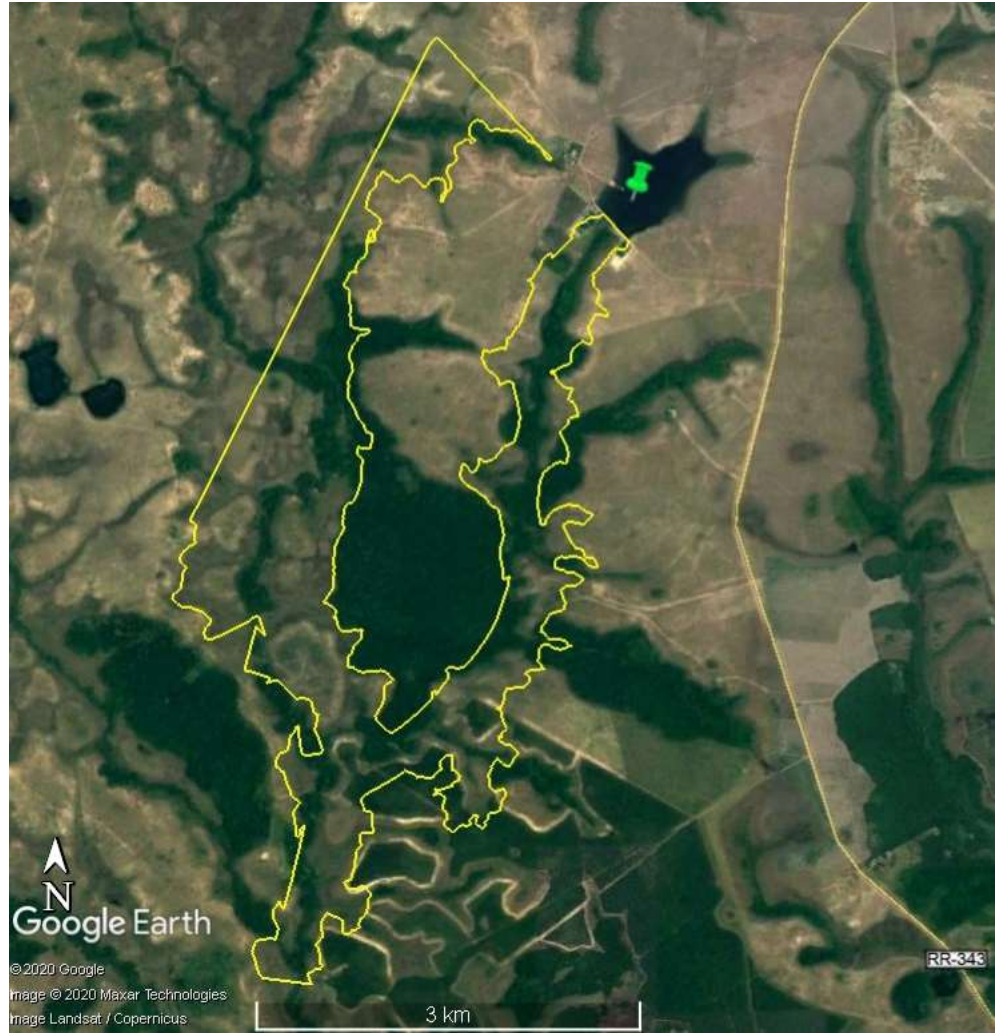

\begin{tabular}{|c|c|c|}
\hline \multicolumn{2}{|c|}{ Legenda } & Observações \\
\hline $\begin{array}{c}\text { Área } \\
\text { inundada }\end{array}$ & $\begin{array}{c}\text { Mancha de 7,5 } \\
\text { km² atinge dois } \\
\text { Igarapés sem } \\
\text { nomes e o Rio } \\
\text { Cauamé, além de } \\
\text { tanques de } \\
\text { piscicultura. }\end{array}$ \\
\hline $\begin{array}{c}\text { Residências } \\
\text { isoladas }\end{array}$ & ษ & $\begin{array}{c}\text { *Sem visibilidade } \\
\text { suficiente para } \\
\text { determinação. }\end{array}$ \\
\hline $\begin{array}{c}\text { Barragem } \\
\text { analisada }\end{array}$ & 8 & \\
\hline
\end{tabular}

Figura 7: Mancha de inundação da barragem Fazenda São Domingos. 


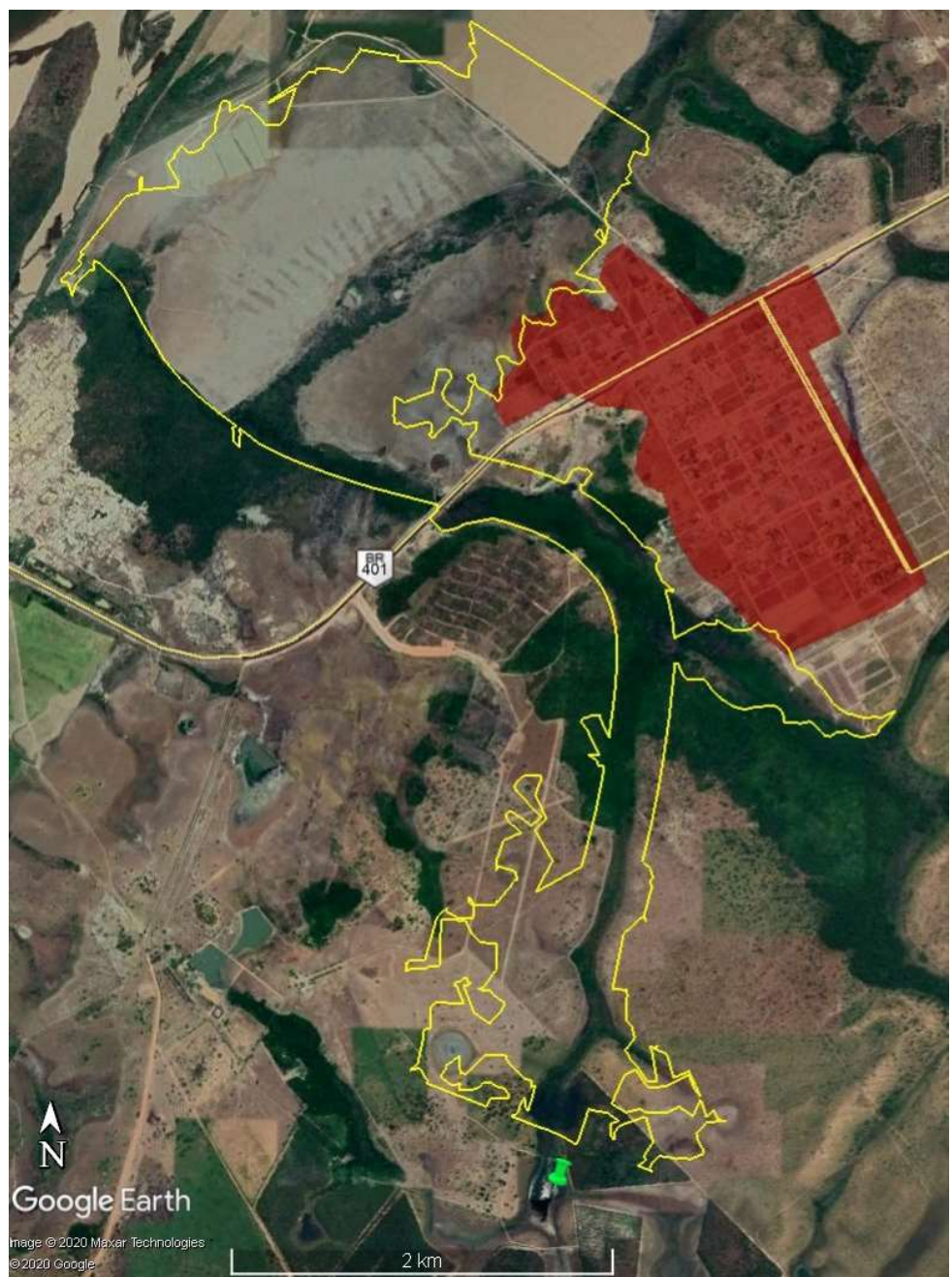

\begin{tabular}{|c|c|c|}
\hline \multicolumn{2}{|c|}{ Legenda } & Observações \\
\hline $\begin{array}{c}\text { Área } \\
\text { edificada }\end{array}$ & $\bigcirc$ & $\begin{array}{c}\text { Cidade de Santa } \\
\text { Cecília/RR. }\end{array}$ \\
\hline $\begin{array}{c}\text { Área } \\
\text { inundada }\end{array}$ & $\begin{array}{c}\text { Mancha de 6,7 km² } \\
\text { atinge Igarapé Santa } \\
\text { Cecília, BR 401 e em } \\
\text { média 10 } \\
\text { residências. }\end{array}$ \\
\hline $\begin{array}{c}\text { Barragem } \\
\text { analisada }\end{array}$ & $\&$ & - \\
\hline
\end{tabular}

Figura 8: Mancha de inundação da barragem Fazenda Umirizal.

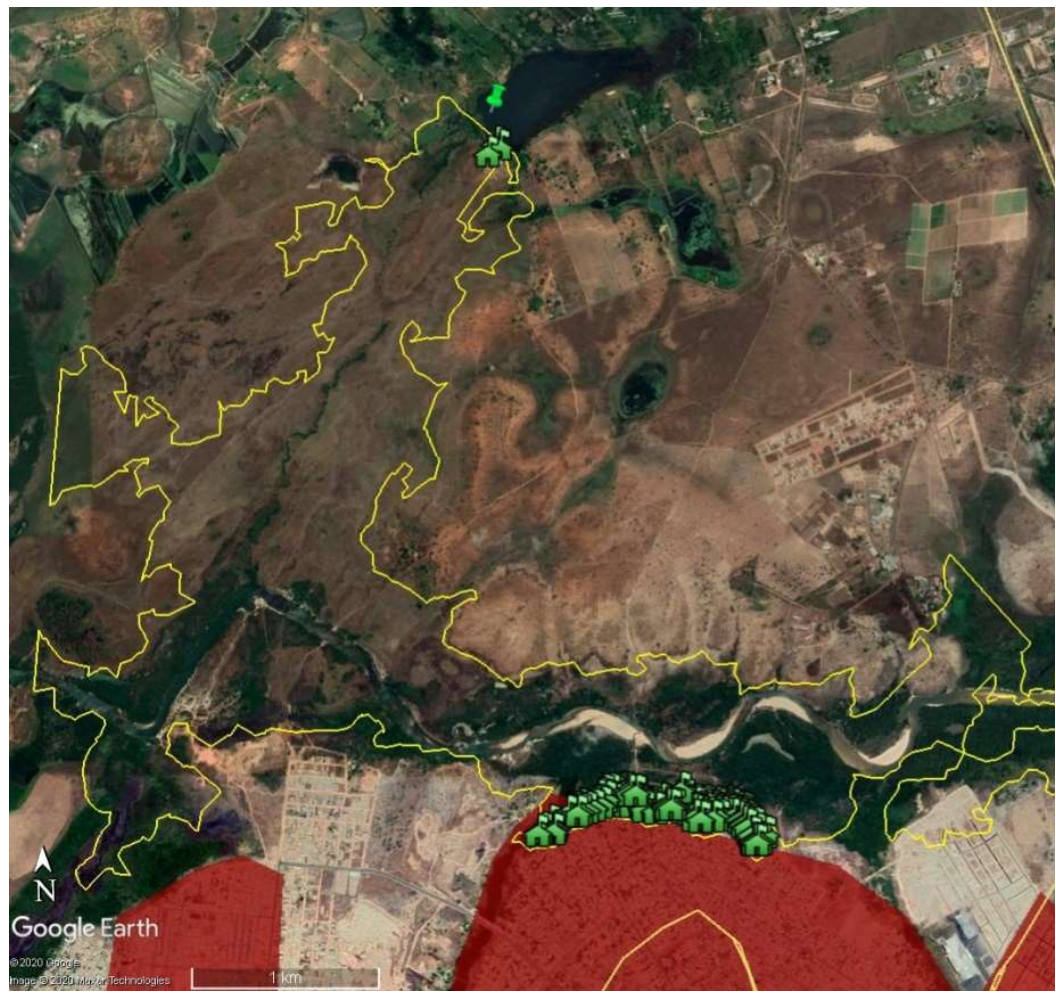

\begin{tabular}{|c|c|}
\hline Legenda & Observações \\
\hline $\begin{array}{c}\text { Área } \\
\text { edificada }\end{array}$ & $\begin{array}{c}\text { Cidade de Boa } \\
\text { Vista/RR. }\end{array}$ \\
\hline $\begin{array}{c}\text { Área } \\
\text { inundada }\end{array}$ & $\begin{array}{c}\text { Mancha de } 7,1 \\
\text { km² atinge o Rio } \\
\text { Cauamé. }\end{array}$ \\
\hline $\begin{array}{c}\text { Residência } \\
\mathrm{s} \text { isoladas }\end{array}$ & $\begin{array}{c}\text { Há } \\
\text { aproximadamen } \\
\text { te } 160 \\
\text { residências. }\end{array}$ \\
\hline $\begin{array}{l}\text { Barragem } \\
\text { analisada }\end{array}$ & - \\
\hline
\end{tabular}

Figura 9: Mancha de inundação da barragem Monte Cristo.

Assim, foram verificados quais parâmetros utilizados pelos critérios das Resoluções CNRH n. 143/2012 e ANA n. 132/2016 e IN Femarh n. 3/2017, bem como das experiências nacionais e internacionais, 
puderam contribuir para formulação da proposta, o que resultou no Quadro 3 abaixo.

Quadro 3: Proposta de classificação quanto ao DPA das barragens para o estado de Roraima.

\begin{tabular}{|c|c|c|}
\hline & Faixa de classificação & Pontos \\
\hline \multirow{4}{*}{$\begin{array}{l}\text { Volume Total do Reservatório } \\
\text { (I) }\end{array}$} & PEQUENO: quando apresenta volume $\leq 5 \mathrm{hm}^{3}$. & 1 \\
\hline & MÉDIO: quando apresenta volume de 5 a $75 \mathrm{hm}^{3}$. & 2 \\
\hline & GRANDE: quando apresenta volume de 75 a $200 \mathrm{hm}^{3}$. & 3 \\
\hline & MUITO GRANDE: quando apresenta volume de maior que $200 \mathrm{hm}^{3}$. & 5 \\
\hline \multirow{4}{*}{$\begin{array}{l}\text { Potencial de perdas de vidas humanas } \\
\text { (II) }\end{array}$} & $\begin{array}{l}\text { INEXISTENTE: quando não existem pessoas permanentes / residentes ou } \\
\text { temporários / transitando na área afetada a jusante da barragem. }\end{array}$ & 0 \\
\hline & $\begin{array}{l}\text { POUCO FREQUENTE: quando não existem pessoas ocupando permanentemente } \\
\text { a área afetada a jusante da barragem, mas existe estrada vicinal de uso local. }\end{array}$ & 4 \\
\hline & $\begin{array}{l}\text { FREQUENTE: quando não existem pessoas ocupando permanentemente a área } \\
\text { afetada a jusante da barragem, mas existe atividade agrícola e/ou industrial, } \\
\text { rodovia municipal, estadual, federal ou outro local e/ou empreendimento de } \\
\text { permanência eventual de pessoas que poderão ser atingidas. }\end{array}$ & 8 \\
\hline & $\begin{array}{l}\text { EXISTENTE: quando não há qualidade nas imagens de satélite, impossibilitando } \\
\text { classificação ou existam pessoas ocupando permanentemente a área afetada a } \\
\text { jusante da barragem, portanto, vidas humanas poderão ser atingidas. }\end{array}$ & 12 \\
\hline \multirow{3}{*}{$\begin{array}{l}\text { Impacto ambiental } \\
\text { (III) }\end{array}$} & $\begin{array}{l}\text { POUCO SIGNIFICATIVO: quando área afetada da barragem não representa área } \\
\text { de interesse ambiental, áreas protegidas em legislação específica ou encontra-se } \\
\text { totalmente descaracterizada de suas condições naturais. }\end{array}$ & 1 \\
\hline & $\begin{array}{l}\text { SIGNIFICATIVO: quando a área afetada inclui áreas de proteção de uso } \\
\text { sustentável (APA, FLONA, RESEX, etc.) ou quando se trata de área de interesse } \\
\text { ambiental e encontra-se pouco descaracterizada de suas condições naturais. }\end{array}$ & 2 \\
\hline & $\begin{array}{l}\text { MUITO SIGNIFICATIVO: quando a área afetada incluir áreas de proteção integral } \\
\text { (ESEC, PARNA, REBIO, etc.), inclusive Terras Indígenas, ou quando for de grande } \\
\text { interesse ambiental em seu estado natural. }\end{array}$ & 5 \\
\hline \multirow{4}{*}{$\begin{array}{l}\text { Impacto socioeconômico } \\
\text { (IV) }\end{array}$} & $\begin{array}{l}\text { INEXISTENTE: quando não existe quaisquer instalações e serviços de navegação } \\
\text { na área afetada por acidente da barragem. }\end{array}$ & 0 \\
\hline & $\begin{array}{l}\text { BAIXO: quando existem de } 1 \text { a } 25 \text { instalações residenciais e comerciais, agrícolas, } \\
\text { industriais ou infraestrutura na área afetada da barragem. }\end{array}$ & 1 \\
\hline & $\begin{array}{l}\text { MÉDIO: quando existem mais de } 25 \text { até } 100 \text { instalações residenciais e comerciais, } \\
\text { agrícolas, industriais ou de infraestrutura na área afetada da barragem. }\end{array}$ & 3 \\
\hline & $\begin{array}{l}\text { ALTO (quando não houver qualidade nas imagens de satélite, impossibilitando } \\
\text { classificação ou quando exista grande concentração de instalações residenciais e } \\
\text { comerciais, agrícolas, industriais, de infraestrutura e serviços de lazer e turismo } \\
\text { na área afetada da barragem ou instalações portuárias ou serviços de navegação, } \\
\text { acima de 100). }\end{array}$ & 8 \\
\hline
\end{tabular}

A partir da proposta apresentada, apenas com adoção de parâmetros quantitativos nas faixas de classificação, sem alteração das respectivas pontuações, bem como do critério mais penalizante presentado em todas as classificações apresentadas neste trabalho - potencial de perda de vidas humanas - foram obtidas as classificações abaixo (Quadro 4 a 10).

Quadro 4: Classificação quanto ao DPA da barragem Ecopark pelo critério proposto.

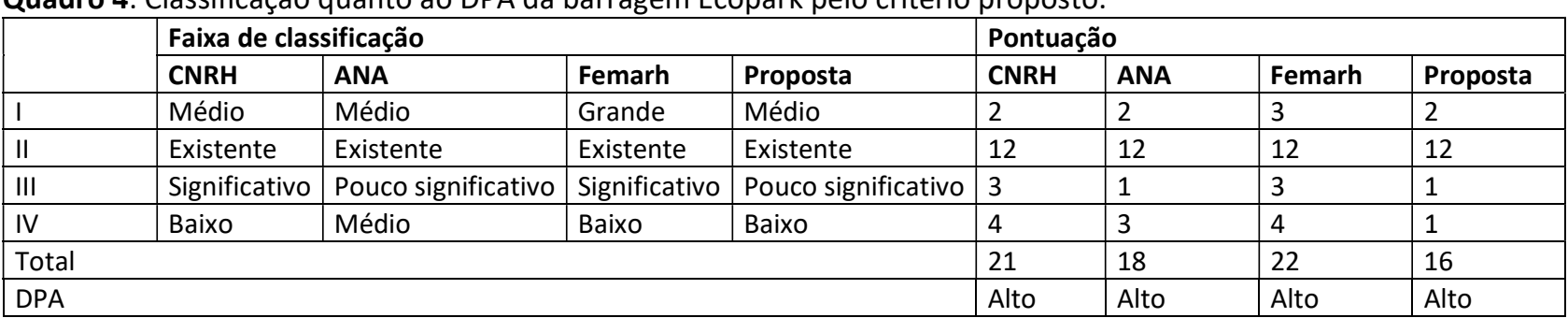

Quadro 5: Classificação quanto ao DPA da barragem da Fazenda Frutal pelo critério proposto.

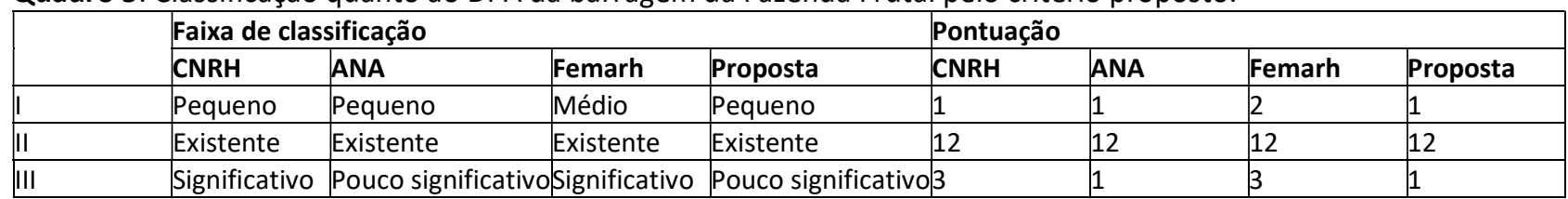




\begin{tabular}{|l|l|l|l|l|l|l|l|l|}
\hline & Faixa de classificação & \multicolumn{2}{l|}{ Pontuação } \\
\cline { 2 - 11 } & CNRH & ANA & Femarh & Proposta & CNRH & ANA & Femarh & Proposta \\
\hline IV & Baixo & Médio & Baixo & Baixo & 4 & 3 & 4 & 1 \\
\hline Total & & & 20 & 17 & 21 & 15 \\
\hline DPA & & Alto & Alto & Alto & Médio \\
\hline
\end{tabular}

Quadro 6: Classificação quanto ao DPA da barragem da Fazenda Nogueira pelo critério proposto.

\begin{tabular}{|l|l|l|l|l|l|l|l|l|}
\hline \multirow{2}{*}{} & Faixa de classificac̃o & Pontuação \\
\cline { 2 - 9 } & CNRH & ANA & Femarh & Proposta & CNRH & ANA & Femarh & Proposta \\
\hline I & Médio & Médio & Grande & Médio & 2 & 2 & 3 & 2 \\
\hline II & Inexistente & Inexistente & Inexistente & Inexistente & 0 & 0 & 0 & 0 \\
\hline III & Significativo & Pouco significativo & Significativo & Pouco significativo & 3 & 1 & 3 & 1 \\
\hline IV & Baixo & Baixo & Baixo & Baixo & 4 & 1 & 4 & 1 \\
\hline Total & & 9 & 4 & 10 & 4 \\
\hline DPA & & Baixo & Baixo & Baixo & Baixo \\
\hline
\end{tabular}

Quadro 7: Classificação quanto ao DPA da barragem da Fazenda Santo Expedito pelo critério proposto.

\begin{tabular}{|c|c|c|c|c|c|c|c|c|}
\hline & \multicolumn{4}{|c|}{ Faixa de classificação } & \multicolumn{4}{|c|}{ Pontuação } \\
\hline & CNRH & ANA & Femarh & Proposta & CNRH & ANA & Femarh & Proposta \\
\hline 1 & Pequeno & Pequeno & Médio & Pequeno & 1 & 1 & 2 & 1 \\
\hline II & Existente & Existente & Existente & Existente & 12 & 12 & 12 & 12 \\
\hline III & Significativo & Pouco significativo & Significativo & Pouco significativo & 3 & 1 & 3 & 1 \\
\hline IV & Baixo & Médio & Baixo & Baixo & 4 & 3 & 4 & 1 \\
\hline \multicolumn{5}{|c|}{ Total } & 20 & 17 & 21 & 15 \\
\hline \multicolumn{5}{|l|}{ DPA } & Alto & Alto & Alto & Médio \\
\hline
\end{tabular}

Quadro 8: Classificação quanto ao DPA da barragem da Fazenda São Domingos pelo critério proposto.

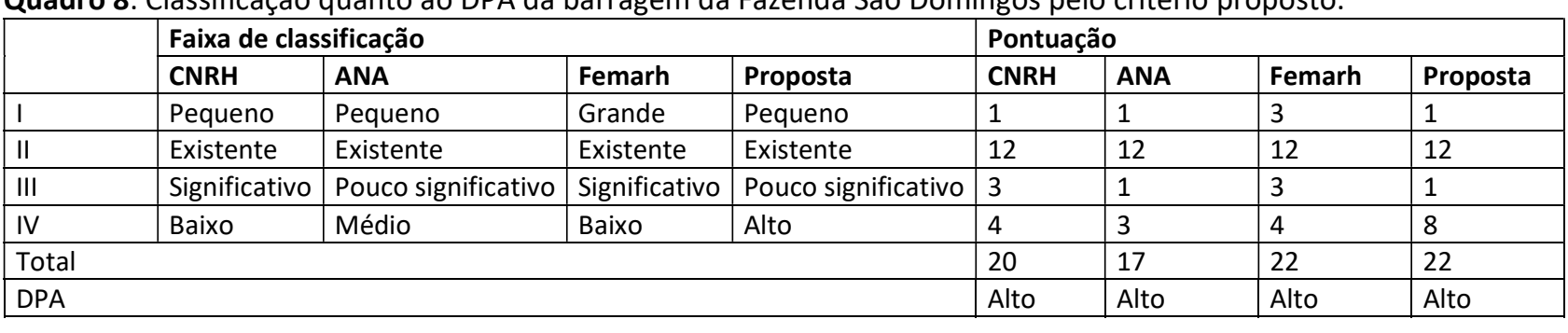

Quadro 9: Classificação quanto ao DPA da barragem da Fazenda Umirizal pelo critério proposto.

\begin{tabular}{|l|l|l|l|l|l|l|l|l|}
\hline \multicolumn{7}{|l|}{} & Faixa de classificação & Pontuação \\
\cline { 2 - 9 } & CNRH & ANA & Femarh & Proposta & CNRH & ANA & Femarh & Proposta \\
\hline I & Pequeno & Pequeno & Pequeno & Pequeno & 1 & 1 & 1 & 1 \\
\hline II & Existente & Existente & Existente & Existente & 12 & 12 & 12 & 12 \\
\hline III & Significativo & Pouco significativo & Significativo & Pouco significativo & 3 & 1 & 3 & 1 \\
\hline IV & Baixo & Baixo & Baixo & 4 & 3 & 4 & 1 \\
\hline Total & Médio & & 20 & 17 & 20 & 15 \\
\hline DPA & & Alto & Alto & Alto & Médio \\
\hline
\end{tabular}

Quadro 10: Classificação quanto ao DPA da barragem Monte Cristo pelo critério proposto.

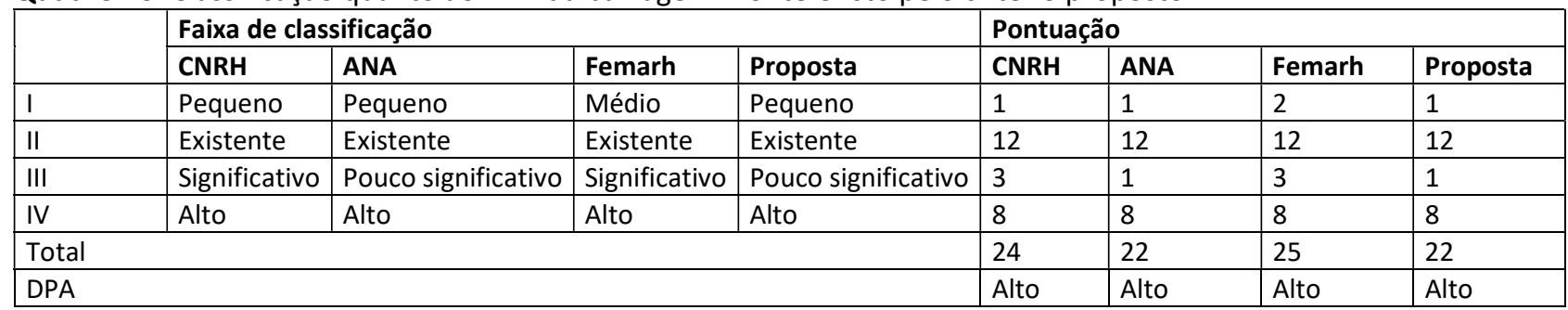

Quanto aos volumes de reservatório das barragens em estudo, destaca-se que apresentam valores entre 0,1 e 8,6 hm³ , com área inundada entre 4,4 e 13,2 km², variando de acordo com a inclinação do terreno e volume da barragem.

Foi observado ainda que os estados analisados adotam as mesmas faixas de classificação presente 
na Resolução CNRH n. 143/2012, ainda que o estado de Rondônia apresente classes com denominações distintas, os intervalos de volumes e as pontuações apresentadas são as mesmas da referida resolução.

As faixas de volumes propostas possibilitou o enquadramento de mais de $70,0 \%$ dos barramentos como volume 'pequeno', de acordo com a Figura 3, perfazendo a realidade das barragens locais, sem penalização excessiva, baseado nos critérios presentes nas Resoluções CNRH n. 143/2012 e ANA n. 132/2016.

Destaca-se que baseado no critério da IN Femarh n. 3/2017, as barragens eram classificadas em aproximadamente 43,0 \% com volume 'médio' e 43,0 \% com 'grande', conforme demonstra Figura 10. Isto, a priori, não resultava em penalização excessiva na classificação geral quanto ao DPA, pois a Femarh não utiliza critérios estabelecidos quanto à delimitação da área afetada. Logo, tal classificação culminava em baixas pontuações gerais de DPA, o que tornava aplicável as faixas de classificações quanto ao volume serem diferentes dos presentes nas Resoluções CNRH n. 143/2012 e ANA n. 132/2016.

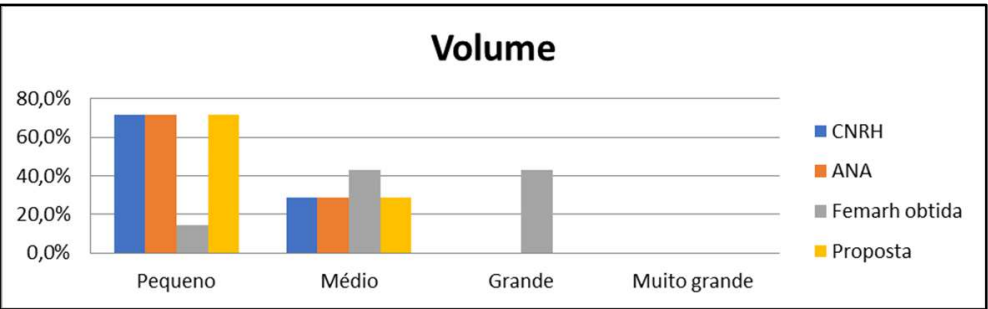

Figura 10: Análise gráfica das classes finais de volume obtidas.

Quanto ao potencial de perdas de vidas humanas, considerando que em todos os critérios apresentados foi priorizada a existência de vida humana como dano máximo de maneira conservadora, não foi observada nenhuma alteração na classificação obtida, conforme representa a Figura 11.

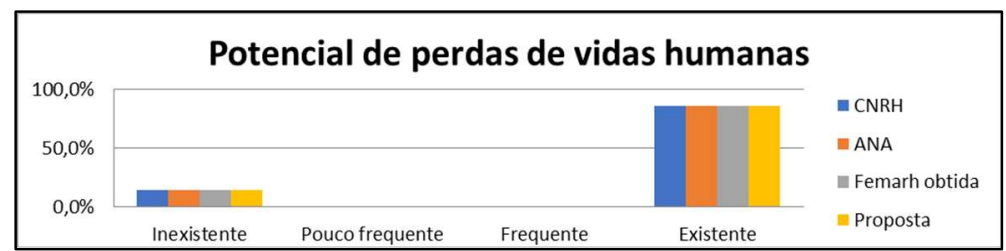

Figura 11: Análise gráfica das classes finais de potencial de perdas de vidas humanas obtidas.

Destaca-se que na barragem da Fazenda São Domingos foi atribuído a faixa de classificação 'existente', de maneira conservadora, em virtude desta não possuir imagens de satélite de boa qualidade que pudessem subsidiar a referida classificação.

No que tange ao impacto ambiental, por ter sido adotado o mesmo critério proposto pela ANA, e devido a todas as barragens analisadas não estarem inseridas em áreas de interesse ambiental, foi obtido o resultado apresentado na Figura 12 abaixo.

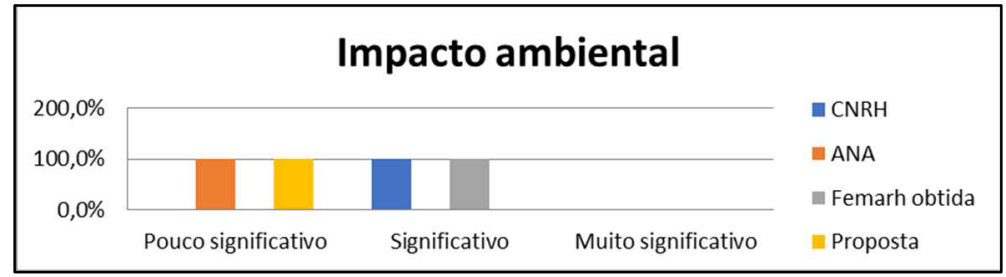

Figura 12: Análise gráfica das classes finais de impacto ambiental obtida. 
Referente ao impacto socioeconômico, a situação encontrada após delimitação da área afetada foi de que, na maioria dos casos, próximo à barragem havia no mínimo quatro residências, indicando ser do proprietário do barramento, não sendo especificado se de uso permanente ou temporário ou simplesmente áreas de armazenamento.

Em mais de 70,0 \% dos casos analisados a mancha de inundação atingiu menos de 25 residências, sendo estas geralmente espaçadas entre si e concentradas nas extremidades da mancha gerada. Somente em um dos casos a mancha atingiu mais de 100 residências, pois atingiu a área edificada da cidade de Boa Vista.

Assim, considerando a situação encontrada e que as barragens em estudo representam aproximadamente $50,0 \%$ das barragens cadastradas junto ao SNISB, as quais contém dados das características técnicas, foram utilizadas as faixas de classificação apresentada pela Resolução ANA n. 132/2016, sendo proposta alteração quantitativa nas faixas de valores de 'Baixo' e 'Médio' impacto socioeconômico (ver Quadro 3).

A alteração foi baseada na realidade local com o intuito de não agravar indevidamente a classificação final da barragem quanto ao DPA e ainda nas experiências de países como Austrália, que divide em duas categorias a população em risco - 2 e 100 pessoas, e acima de 100 pessoas (QUEENSLAND, 2019), Canadá que divide a população em seis categorias variando de 0 a 10.000 (QUÉBEC, 2019) e Portugal que divide em três categorias - 0 a 25 pessoas, acima de 25 e restante das barragens (PORTUGAL, 2007), os quais trabalham com valores semelhantes aos propostos.

Deste modo, observou-se que, quanto ao impacto socioeconômico, mais de 70,0\% dos barramentos apresentou impacto 'baixo', quer seja por existir pequena aglomeração de pessoas, quer seja por possuir apenas instalações agrícolas como piscicultura no local (ver Figura 13). Ademais, destaca-se que para a barragem da Fazenda São Domingos foi atribuído a faixa de impacto 'alto', de maneira conservadora, em virtude desta não possuir imagens de satélite de boa qualidade que pudessem subsidiar a referida classificação de maneira correta.

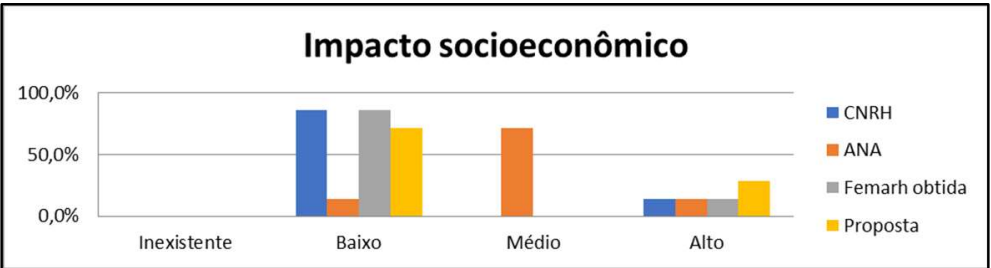

Figura 13: Análise gráfica das classes finais de impacto socioeconômico obtido.

A classificação obtida quando aplicada a proposta apresentada neste estudo, resultou que $42,9 \%$ das barragens foram classificadas com DPA 'médio' e 42,9 \% com DPA 'alto' (ver Figura 14). Logo, conclui-se que aproximadamente $86,0 \%$ das barragens analisadas estão sob a égide da Lei n. 12.334/2010, ou seja, é aplicável a PNSB e todas as Resoluções da ANA sobre segurança de barragens. 


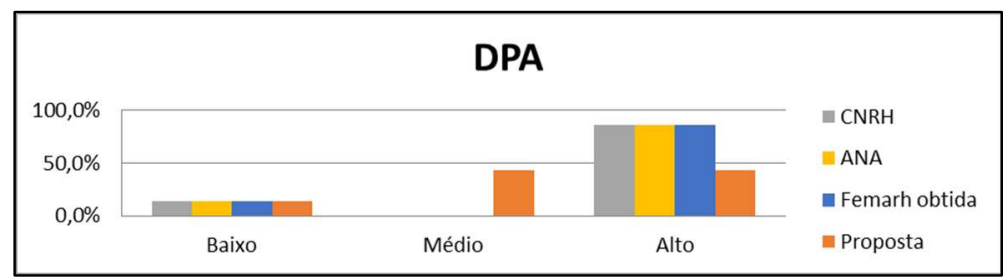

Figura 14: Análise gráfica das classes finais de DPA obtidas.

\section{CONCLUSÕES}

Quando se iniciou o presente estudo, constatou-se que o estado de Roraima não possuía um critério de classificação quanto ao DPA estabelecido, com ausência de definição da metodologia de delimitação da área afetada para aplicação dos critérios presentes na IN Femarh n. 3/2017. Além disso, havia barragens irregulares não cadastradas que necessitavam de cadastro e análise quanto ao DPA. Assim, considerou-se importante propor um modelo de classificação quanto ao DPA para o estado de Roraima, de modo a se obter uma classificação mais adequada à realidade local por meio de critérios objetivos de avaliação, contribuindo inclusive para elaboração do PSB.

A análise comparativa entre os resultados obtidos por meio da aplicação dos critérios estabelecidos nas Resoluções CNRH n. 143/2012 e ANA n. 132/2016 possibilitou concluir que havia uma penalização em excesso já que mais de 85,0\% das barragens obtiveram classificação de DPA 'alto' mesmo que, mais de 70,0 $\%$ dos barramentos, fosse classificado como volume 'pequeno'.

Tal fato ocorreu em virtude de ambos os critérios adotarem, de modo conservador, penalização máxima quando há existência de uma ou mais vidas humanas na área afetada e por não haver distribuição quantitativa adequada à realidade das barragens do estado quanto ao impacto socioeconômico. Destaca-se que este é relacionado à existência de instalações residenciais, agrícolas, entre outros, ou seja, também envolve existência de vidas humanas. Logo, a classificação presente nas Resoluções CNRH n. 143/2012 e ANA n. 132/2016 culminou penalizando duplamente as barragens em estudo.

No que tange a comparação entre a classificação das barragens quanto ao DPA, utilizando o método simplificado de geração de mancha da ANA para delimitação da área afetada, e a classificação feita pela Femarh possibilitou concluir que ou a área afetada considerada pela Femarh foi subestimada ou o método simplificado sobrestimou bastante a área. Contudo, de maneira conservadora, foi adotada referida metodologia por possuir respaldos internacionais e nacionais, e por terem sido utilizadas imagens do satélite ALOS PALSAR, cuja resolução espacial é melhor que a do SRTM proposta inicialmente no método.

A proposta apresentada neste estudo ponderou os critérios já estabelecidos a nível nacional e internacional, resultando em alteração das faixas de classificação de volume utilizadas pela Femarh, por ser observado que havia penalização em excesso quando associada à metodologia simplificada de geração de manchas. Quanto ao potencial de perdas de vidas humanas, não foi realizada alteração em virtude de ser mantida classificação conservadora adotada em todo o Brasil. No que tange ao impacto ambiental, foi adotada o critério apresentado na Resolução ANA n. 132/2016, uma vez que este apresentou pontuações adequadas às barragens estudas. Por fim, quanto ao critério socioeconômico, foram inseridos critérios 
quantitativos, inexistentes na Resolução CNRH n. 143/2012 e IN Femarh n. 3/2017, de modo a reduzir a discricionariedade por parte do órgão fiscalizador.

A classificação obtida quando aplicada a proposta apresentada neste estudo, resultou que aproximadamente $86,0 \%$ das barragens analisadas estão sob a égide da Lei n. $12.334 / 2010$. Isto se deve ao fato de a existência de vidas humanas e o impacto socioeconômico ter ocorrido por meio da identificação de edificações existentes nas imagens de satélites, sem distinção entre uso permanente, sazonal ou ainda se são residências ou áreas de depósito.

A metodologia adotada nesta pesquisa foi do tipo descritivo e exploratório, uma vez que houve revisão bibliográfica quanto ao tema estudado, destacando a insuficiência de informações a nível estadual. Foi utilizada a abordagem qualitativa dos dados, porquanto ocorreu por meio da análise crítica dos resultados obtidos de diferentes critérios de classificação aplicados que culminaram no modelo de proposta de classificação apresentado neste trabalho. Destaca-se que os procedimentos de pesquisa foram do tipo bibliográfico e documental.

Além disso, diante da metodologia proposta, percebeu-se que para delimitação da área afetada, havia outros métodos a serem seguidos. Contudo, de acordo com Banco Mundial (2014), o método simplificado, aplicado inclusive às pequenas barragens, o qual envolve um nível razoável de automação de procedimentos, apresentou resultados satisfatórios quando comparado com o modelo HEC-RAS (mais complexo). Ressalta-se que este último modelo só é útil quando há informação topográfica e rugosidade superficial com algum detalhe, fato este que impossibilitou sua aplicação no presente estudo.

Acresce salientar ainda que foi utilizado, para aplicação da metodologia simplificada, dados do MDE que contemplam cotas, vegetação e edificações presentes no terreno. Contudo, segundo Banco Mundial (2014), ainda é adequado considerar estes dados digitais de terreno na falta de melhor informação e considerando que tal metodologia é aplicada apenas para permitir a classificação das barragens em termos de DPA. Ademais, foram adotadas correções propostas pela ANA (2017a) para os devidos ajustes, tal como o buffer de 150,0 m utilizado.

Visando não haver penalização excessiva de maneira desnecessária, recomenda-se que sejam verificadas in loco as edificações inseridas na área afetada, registrando o seu uso e ocupação, descartandoas da lista de ocorrências se não se tratar de fato duma habitação permanente, como por exemplo, em casos de palheiros e armazéns, ou se estiver abandonada ou inabitável (em ruína). Em seguida deverá ser feita a reclassificação quanto ao DPA, a qual poderá conduzir a uma redução da classe de 'alto' para 'médio' ou mesmo para 'baixo'.

Ressalta-se que, ao contrário do que dispõe a IN Femarh n. 3/2017 quanto à definição de DPA 'baixo', recomenda-se que as barragens sejam classificadas quanto ao DPA de acordo com o dano causado na área afetada, obtida por meio da metodologia simplificada, e não apenas em função do volume da barragem ser enquadrado como 'pequeno' ou de parâmetros relacionados ao comprimento do reservatório.

Quanto à mancha de inundação obtida, observou-se que na maioria dos casos houve inundação parcial de afluentes próximos ao curso d'água barrado. Assim, sugere-se que sejam realizados estudos 
futuros quanto ao impacto gerado em termos de erosão, assoreamento, supressão vegetal, qualidade da água, entre outros, de modo a avaliar a referida relevância do impacto ambiental para classificação quanto DPA.

Por fim, sugere-se que sejam realizados estudos futuros voltados para viabilidade de classificação das barragens com abordagem baseada no risco informado, por esta já ser prática padrão ou em vias de adoção em outros países, a qual analisa a probabilidade de ruptura e suas consequências, ao invés de classificação adotada hoje no Brasil em função do porte, uso e aspectos físicos.

\section{REFERÊNCIAS}

ANA. Agência Nacional das Águas. Resolução n. 236, de 30 de janeiro de 2017. ANA estabelece a periodicidade de execução ou atualização, a qualificação dos responsáveis técnicos, o conteúdo mínimo e o nível de detalhamento do Plano de Segurança da Barragem, das Inspeções de Segurança Regular e Especial, da Revisão Periódica de Segurança de Barragem e do Plano de Ação de Emergência. Brasília: DOU, 2017.

ANA. Agência Nacional das Águas. Cadastros de barragens realizados no Relatório de Segurança de Barragens. Brasília: ANA, 2017a.

ANA. Agência Nacional das Águas. Curso sobre metodologia simplificada para definição da mancha de classificação do Dano Potencial Associado (DPA) da barragem. Brasília: ANA, 2017b.

ANA. Agência Nacional das Águas. Programa Nacional de Consolidação do Pacto Nacional pela Gestão das Águas Progestão. Brasília: ANA, 2020.

ANDERÁOS, A.; ARAÚJO, L. M. N.; NUNES, C. M..

Classificação de barragem quanto à categoria de risco e ao dano potencial associado - um exercício. In: SIMPÓSIO BRASILEIRO DE RECURSOS HÍDRICOS, 10. Anais. Bento Gonçalves, 2013. p. 1-8.
BANCO MUNDIAL. Classificação de barragens reguladas pela Agência nacional de águas (Produto 6). Brasília: ANA, 2014a.

FEMARH. Fundação Estadual do Meio Ambiente e Recursos Hídricos. Instrução Normativa n. 3, de 20 de dezembro de 2017. Critérios e os procedimentos para a classificação, implantação e a revisão periódica de segurança de barragens de acumulação de água, contenção de rejeitos e resíduos de domínio do estado de Roraima. Boa Vista: DOE, 2018.

IBGE. Instituto Brasileiro de Geografia e Estatística. Bases cartográficas contínuas. IBGE, 2011.

PETRY, A.; LAUS, F.; ANDERÁOS, A.; BONFIM, M.. Classificação de barragens quanto ao dano potencial associado: a experiência da agência nacional de águas. In: INTERNATIONAL DAM WORLD CONFERENCE, 3. Anais. Foz do Iguaçu, 2018.

PORTUGAL. Decreto-Lei n. 344, de 15 de outubro de 2007. Aprova o regulamento de segurança de barragens. Portugal: Diário da República, 2007.

QUÉBEC. Dam Safety Regulations. Québec, 2019.

QUEENSLAND. Water Supply (Safety and Reliability) Act 2008. State of Queensland, 2019.

A CBPC - Companhia Brasileira de Produção Científica (CNPJ: 11.221.422/0001-03) detém os direitos materiais desta publicação. Os direitos referem-se à publicação do trabalho em qualquer parte do mundo, incluindo os direitos às renovaç̃̃es, expansões e disseminações da contribuição, bem como outros direitos subsidiários. Todos os trabalhos publicados eletronicamente poderão posteriormente ser publicados em coletâneas impressas sob coordenação da Sustenere Publishing, da Companhia Brasileira de Produção Científica e seus parceiros autorizados. Os (as) autores (as) posteriormente ser publicados em coletâneas impressas sob coordenação da Sustenere Publishing, da Companhia Brasileira de Produção Científica e seus parce
preservam os direitos autorais, mas não têm permissão para a publicação da contribuição em outro meio, impresso ou digital, em português ou em tradução. 